\title{
VITAMIN CONTENT OF MARINE RED ALGA CHAMPIA PARVULA
}

\author{
VINOTHKUMAR R ${ }^{1}$, MURUGESAN S ${ }^{1 *}$, SIVAMURUGAN V ${ }^{2}$
}

${ }^{1}$ Department of Botany, Division of Algal Biotechnology and Bionano Technology, Pachaiyappa's College, Chennai, Tamil Nadu, India. ${ }^{2}$ Department of Chemistry, Pachaiyappa's College, Chennai, Tamil Nadu, India. Email: smurugesan5@gmail.com

Received: 24 August 2019, Revised and Accepted: 24 August 2019

ABSTRACT

Objective: The current investigation focuses on determining the vitamin content of marine red alga Champia parvula.

Methods: Vitamins were divided and analyzed using Milichrom A-02 LC and multiwavelength ultraviolet visible as a detector. A 2 mm (ID)×250 mm (l) column was used to filter comprising C18 in the inverse stage used for separation.

Results: The results suggest that the seaweed, $C$. parvula, contains $0.583 \pm 0.01,3.43 \pm 0.01,4.95 \pm 0.01,1.95 \pm 0.01,6.33 \pm 0.00,174.74 \pm 0.01$, and $15.75 \pm 0.01 \mu \mathrm{g}$ of Vitamin A, B1, B5, folic acid, B12, C, and E, respectively, per gram of dry weight of the seaweed.

Conclusion: The findings indicate that the seaweed, C. parvula, has a higher nutritional value and could be used as great dietary supplements for vitamins.

Keywords: Marine algae, vitamins, Champia parvula.

(C) 2019 The Authors. Published by Innovare Academic Sciences Pvt Ltd. This is an open access article under the CC BY license (http://creativecommons. org/licenses/by/4. 0/) DOI: http://dx.doi.org/10.22159/ajpcr.2019.v12i10.35134

\section{INTRODUCTION}

Seaweeds are a precious source of food as they contain protein, lipids, vitamin, and minerals [1]. Seaweeds are not only a helpful food source for humans, whole crops and seaweed mixtures have been used in animal nutrition [2-4]. The dietary characteristics of seaweed are poorly understood and are usually assessed from the chemical composition [5]. A few reports has been published in the quantitative dietary composition studies in the Egyptian seaweeds [6-8]. Given their potential for use as food and fodder, there is an increasing need to evaluate the food quality of marine algae. The edibility value of algae is derived not only from the amount of nutrients supplied but also from the essential vitamins contained. Before identifying the vitamins, the significance of keeping a good diet was recognized. Vitamins are nutrients and each plays a part in creating and retaining a healthy, functional human being. Vitamins are vital for various chemical and physiological tasks in the human body. Seaweeds are naturally a higher supply of B complex (B1, B2, B3, B6, B9, and B12) [9]. Vitamins are very essential for all organisms as they present in the precursors as enzyme cofactors that are essential for metabolism. Seaweeds comprise both water-soluble vitamins (Vitamin B and Vitamin C) and fat-soluble vitamins (Vitamins A, D, E, and K) [10]. The objective of this research is to evaluate the vitamin content of the marine red alga Champia parvula.

\section{METHODS}

\section{Collection and authentication}

C. parvula (C. Agardh) was collected from Mandapam, Mannar Gulf, Mandapam Coast, Ramnad, Tamil Nadu. The morphological nature of the alga was referred to with the Rhodophyta monograph [11] and was authenticated by Dr. M. Baluswami, Retired Professor, Department of Botany, Madras Christian College, Chennai, Tamil Nadu, India.

\section{Processing of collected sample}

In addition to epiphytes, sand particles, and shells, the gathered seaweeds were washed with seawater to eliminate dirt and debris. Then, the seaweeds were cleaned with running tap water followed by distilled water and dried completely at room temperature under shade.
The subsequent dried material was approximately powdered (passing through 40 size sieve) and used for further considerations.

\section{Preparation of extract}

The red seaweed extract $C$. parvula was obtained by adding methanol to the round bottom flask followed by the addition of $50 \mathrm{~g}$ of seaweed powder and was subject to Soxhlet apparatus for $72 \mathrm{~h}$ at $64^{\circ} \mathrm{C}$. C. parvula extract (representing both reduced polar, polar, and nonpolar elements) was pooled together and the solvents removed under condensed pressure using a rotary flash evaporator (Superfit, India). The crude extract has been quantified and used for further examination.

\section{Reagents and apparatus}

Vitamins were isolated using multiwavelength ultraviolet detection on a Milichrom A-02 fluid chromatograph (ZAO EcoNova, Novosibirsk, Russia). A $2 \mathrm{~mm}$ (ID) $\times 250 \mathrm{~mm}$ (I) column with the reversed-phase sorbent Nucleosil 100-5 C18 (Macherey-Nagel, Germany) was used. We used the gradient elution mode for water-soluble vitamins and the isocratic mode for fat-soluble vitamins (elution conditions are shown in the text below). The solution acidity was monitored with a precision of $0.2 \mathrm{pH}$ using an Anion $7000 \mathrm{pH}$ meter (ZAO Infraspak-Analit, Novosibirsk, Russia).

As vitamin reference, we used pure biotin (Vitamin H), nicotinic acid, nicotinamide, calcium pantothenate, pyridoxine hydrochloride (Vitamin B6), folic acid (Vitamin B9), riboflavin (Vitamin B2), thiamine hydrochloride (Vitamin B1), and cyanocobalamin (Vitamin B12) as well as pharmaceutical preparations, 30\% solution of $\alpha$-tocopherol acetate in oil (Vitamin E) and $3.44 \%$ solution of retinol acetate in oil (Vitamin A). We used 0.4 M lithium perchlorate aqueous solution with $\mathrm{pH} 2.4$ (solution no. 1) and $0.1 \%$ butyl hydroxytoluene solution in methanol (solution no. 2). Stock solutions for calibration mixtures were prepared in the following solvents: Vitamins B1, B2, B6, B12, and nicotinic acid and calcium pantothenate in solution no. 1 with the addition of solution no. 2 with volume ratio 99:1; Vitamin $\mathrm{H}$ in solution no. 2; and Vitamin B9 in lithium perchlorate solution with $\mathrm{pH}$ 8 (solution no. 3). 
The solution's pH was adjusted with lithium hydroxide. Acetates of Vitamin A and E have been dissolved in propanol. Stock solutions of water-soluble vitamins were filtered if necessary and mixed to prepare the calibration mixture with the following concentrations of vitamins $\left(\mathrm{mg} / \mathrm{cm}^{3}\right)$ : B1, 0.05; B2, 0.08; B6, 0.1; B12, 0.05; $\mathrm{H}, 0.1$; nicotinic acid (or nicotinamide), 0.6 ; and calcium pantothenate, 0.6 (stock reference mixture). This combination was diluted with solution no. 1 to prepare calibration solutions with reduced vitamin levels. For Vitamin B9, calibration was performed separately starting from 0.02 $\mathrm{mg} / \mathrm{mL}$ concentration and diluting this solution with solution no. 3 . An analogous combination of fat-soluble vitamins was prepared in solution no. 2; Vitamin A and E levels were $0.2,0.03$, and $1.5 \mathrm{mg} / \mathrm{mL}$, respectively. This combination was diluted with solution no. 2 to obtain reduced levels. For each vitamin, the smallest concentration was onetenth of the greatest concentration.

\section{Sample preparation}

Samples for the determination of vitamins were drawn and prepared in accordance with regulations for pharmaceutical preparations and premixes [12]. Premixes and capsule contents were crushed in a porcelain mortar until a homogeneous mixture was acquired. For the determination of water-soluble vitamins, a mixture of solution no. 1 and solution no. 2 with the volume ratio 19:1 was added to a weighed portion of the triturated sample (0.1-0.2 g) and stirred in the dark at $\mathrm{pH} 5-5.5$ and temperature $30-35^{\circ} \mathrm{C}$ for $10 \mathrm{~min}$. When dissolution of the sample parts did not attain the required $\mathrm{pH}$, it was modified to the necessary value with a lithium hydroxide solution. The $\mathrm{pH}$ of the sample was adapted to 2.4 after dissolution for $10 \mathrm{~min}$ at $\mathrm{pH} 5.5$, and dissolution proceeded for 10 min more. Added amounts were taken into consideration when calculating vitamin levels. $5 \mathrm{~mL}$ of solution no. 2 was added in $0.05-0.1 \mathrm{~g}$ of the sample for the determination of fatsoluble vitamins, kept in the dark for $2 \mathrm{~h}$ in a tightly shut vessel and then stirred at room temperature for $20 \mathrm{~min}$. Before injection into the column, samples were centrifuged and analyzed within $1 \mathrm{~h}$.

\section{Statistical analysis}

All studies were conducted in triplicates and vitamin investigation information were subjected to variance assessment (ANOVA) using SPSS version (17.0). The results were presented as mean \pm standard error.

\section{RESULTS}

C. parvula has been observed to contain Vitamin A, Vitamin B12, Vitamin B1, Vitamin B2, Vitamin C, Vitamin E, niacinamide, folic acid, and calcium pantothenate. It includes the most notable measure of Vitamin C $(174.74 \pm 0.01 \mu \mathrm{g} / \mathrm{g}$ dry wt.) relative to the other vitamins and Vitamin A $(0.583 \pm 0.01 \mu \mathrm{g} / \mathrm{g}$ dry wt.) was present in a lesser amount (Table 1). Based on the dry weight of the specimens, calcium pantothenate, folic acid, Vitamin B12 and Vitamin B2 were present in $4.95 \pm 0.01,1.95 \pm 0.01,6.33 \pm 0.00$ and $6.16 \pm 0.01 \mu \mathrm{g} / \mathrm{g}$, respectively.

\section{DISCUSSION}

Vitamins are fundamental precursors for enzyme cofactors and are essential for various chemical and physiological activities in the human body. Marine algae include both water- and fat-soluble vitamins. These include Vitamins A, B, C and E. Many algae have vitamin auxotrophy, which is failed to synthesize an organic nutrient. The vitamin content of $C$. parvula in the current study was revealed to be a decent source of Vitamins A and E as well as Vitamin B6, Vitamin B12 and Vitamin C.

Vitamin A (Retinol) is needed by humans for the ordinary functioning of the visual system. The second primary role of Vitamin A is to protect the body's development and cellular epithelial integrity and immune function. Seaweeds are known to be a useful source of Vitamin A. Norziah and Ching [13] revealed Gracilaria changii Vitamin A activity. In the current study, C. parvula showed $0.583 \pm 0.01 \mu \mathrm{g} / \mathrm{g}$ dry wt. of Vitamin A.

Vitamin B1 (thiamine) is a water-soluble member of the Vitamin B complex. Its dynamic frame is a coenzyme called thiamine
Table 1: Vitamin content of Champia parvula ( $\mu \mathrm{g} / \mathrm{g}$ dry wt.)

\begin{tabular}{lll}
\hline S. No. & Vitamins & Mean \pm SE \\
\hline 1. & Vitamin A (Retinol) & $0.583 \pm 0.01$ \\
2. & Vitamin B1 (Thiamine) & $3.43 \pm 0.01$ \\
3. & Vitamin B2 (Riboflavin) & $6.16 \pm 0.01$ \\
4. & Vitamin B3 (Niacinamide) & $12.04 \pm 0.02$ \\
5. & Vitamin B5 (Calcium pantothenate) & $4.95 \pm 0.01$ \\
6. & Vitamin B9 (Folic acid) & $1.95 \pm 0.01$ \\
7. & Vitamin B12 (Cobalamin) & $6.33 \pm 0.01$ \\
8. & Vitamin C (Ascorbic acid) & $174.74 \pm 0.01$ \\
9. & Vitamin E ( $\alpha$-tocopherol) & $15.75 \pm 0.01$ \\
\hline
\end{tabular}

Values are expressed as mean \pm SEM, $n=3$ as ANOVA test $p<0.05 \%$ level.

SEM: Standard mean of the error

pyrophosphate, which is involved in changing pyruvate to acetyl coenzyme A during metabolism [14].

The content of Vitamin B1 in C. parvula was $3.43 \pm 0.01 \mu \mathrm{g} / \mathrm{g}$ dry wt. Seaweeds are generally an outstanding resource of constituents of Vitamin B such as B1, B2, and B12 [15]. The vitamin structure changes with numerous components including species, geographic zone, and seasonal and environmental parameters [16-19]. Consequently, Padina tetrastromatica recorded a greater quantity of Vitamin B1, which was greater than C. parvula [20]

\section{Vitamin B5 (pantothenic acid)}

Pantothenic acid content of $C$. parvula was $4.95 \pm 0.01 \mu \mathrm{g} / \mathrm{g}$ dry wt. Vitamin B5 is concerned with the oxidation of fatty acids and carbohydrates [21].

\section{Vitamin B9 (folic acid)}

Folic acid functions as a coenzyme in the form of tetrahydrofolate and is needed for ordinary cell division, particularly during pregnancy and infancy where quick development is essential. Folic acid also helps to produce red blood cells in erythropoiesis [22]. Vitamin B9 is chosen to treat the effects of aging, chronic fatigue syndrome, and anemia [18]. C. parvula includes $1.95 \pm 0.01 \mu \mathrm{g} / \mathrm{g}$ dry wt. folic acid. The marine algae Undaria pinnatifida include a greater quantity of folic acid than those found in the current examination $[23,24]$.

Sea vegetables are also an immense supply of B-group vitamins (particularly B1 and B12). This could give one of the few vegetarian solutions to Vitamin B12 in the eating routine [15]. Higher plants do not require or combine cobalamin [25]. Pyropia yezoensis contains as much as $0.06 \mathrm{mg}$ of Vitamin B12 (100 g) $)^{-1}$ algal dry wt., almost identical to that observed in the liver of bovine animals [26]. Takenaka established that nourishing nori with Vitamin B12-deficient rats produced a 1.9fold increase in hepatic levels of aggregate B12 compared to those without nori supplementation. In the present inquiry, the fullness of Vitamin B12 is irrefutable C. parvula $(6.33 \pm 0.00 \mu \mathrm{g} / \mathrm{g}$ dry wt.).

It is a water-soluble vitamin and is a cofactor for enzymes connected with collagen biosynthesis; carnitine and neurotransmitters in vitro [27] and can suppress multiple kinds of reactive oxygen species in aqueous settings. The algae are a useful source of Vitamin C [20,28].

In the current examination, C. parvula showed plenty of Vitamin C $(174.74 \pm 0.01 \mu \mathrm{g} / \mathrm{g}$ dry $\mathrm{wt}$.). This contributes to the evidence that seaweeds can provide dietary intake in a balanced diet. This outcome showed that the experimental alga could be used as a complement to boost the immune system.

Vitamin E is a lipid-soluble vitamin called $\alpha$-tocopherol, which plays a main role in cancer prevention and inhibition. Vitamin $\mathrm{E}$ has been examined for cancer such as colon cancer, pulmonary cancer, prostate cancer, and breast cancer [29]. The concentration of tocopherol in algae basically represents the equilibrium between the algae biosynthetic and accumulating ability for tocopherol and fundamentally represents the rate at which it is transformed into quinine, as it is referred to 
mainly as an antioxidant to preserve the physiological lipid profile in membranes [30,31], and Panayotova and Stancheva (2013) reported Vitamin E content in Cystoseria [31]. The amount of Vitamin E in these marine algae was better than that enlisted in food known as wealthy $\alpha$-tocopherol. In the current examination, $C$. parvula showed a Vitamin E content of $15.75 \pm 0.01 \mu \mathrm{g} / \mathrm{g}$ dry wt. Vitamin $\mathrm{E}$ is considered for antioxidant activity. Appearing to help counteract cardiovascular illnesses was $\alpha$ - and $\pi$-tocopherols.

\section{CONCLUSION}

Marine algae may be a natural source of vitamins. Seaweeds have an elevated amount of vitamins and are an outstanding source of vitamins. It is found that $C$. parvula is a good source of vitamins that can be used in the nutraceutical and pharmaceutical industries. The examination has consequences for where algae can obtain a vitamin that is vital to fuel marine life.

\section{AUTHORS' CONTRIBUTIONS}

All authors have contributed to the completion of this research work.

\section{CONFLICTS OF INTEREST}

Authors have none to declare.

\section{REFERENCES}

1. Marinho-Soriano E, Fonseca PC, Carneiro MA, Moreira WS. Seasonal variation in the chemical composition of two tropical seaweeds. Bioresour Technol 2006;97:2402-6.

2. Indergaard M, Minsaas J. Animal and human nutrition. In: Guiry MD, Blunder G, editors. Seaweed Resources in Europe: Uses and Potential. Hoboken, New Jersey: John Wiley and Sons; 1991. p. 22-64.

3. Ventura MR, Castanon JI. The nutritive value of seaweed (Ulva lactuca) forgoats. Small Rumin Res 1998;29:325-7.

4. McHugh DJ. A guide to Seaweeds Industry, FAO Fisheries Technical Paper, No. 441. Rome: Food and Agriculture Organization; 2003. p. 105.

5. Mabeau S, Fleurence J. Seaweed in food products: Biochemical and nutritional aspects. Trends Food Sci Technol 1993;4:103-7.

6. Abdel-Fatta AF, Edrees M. Composition of some brown algae as influenced by seasonal variation. Phytochemistry 1973;9:721-4.

7. Abdel-Fattah AF, Hussein MM, Fouad ST. Carbohydrates of the brown seaweed Dictyota dichotoma. Phytochemistry 1978;17:741-3.

8. Hussein MM, Abdel-Aziz A, Salem HM. Composition of Enteromorpha intestinalis as influenced by seasonal variation. Egypt J Bot 1981;24:131-5.

9. Kim SK, Taylor S, editor. Marine medicinal foods: Implications and applications, macro and microalgae. In: Food and Nutrition Research. San Diego, CA: Academic Press; 2011. p. 358-63.

10. Sanchez-Machado DI, LopeZ-Cervantes J, Lopez-hernandez J, PseiroLosada P. Fatty acids, total lipid, protein and ash contents of processed edible seaweeds. Food Chemist 2004;85:439-44.

11. Desikachary TV, Krishnamurthy V, Balakrishnan MS. Rhodophyta. Vol. 2. Chennai: Madras Science Foundation; 1998. p. 359.

12. Kozhanova LA, Fedorova GA, Baram GI. Determination of water and fat-soluble vitamins in multivitamin preparations by high-performance liquid chromatography. J Anal Chem 2002;57:40-5.

13. Norziah MH, Ching CY. Nutritional composition of edible seaweed Gracilaria changgi. Food Chem 2000;68:69-76.

14. Fattal-Valevski A, Kesler A, Sela BA, Nitzan-Kaluski D, Rotstein M, Mesterman R, et al. Outbreak of life-threatening thiamine deficiency in infants in Israel caused by a defective soy-based formula. Pediatrics 2005; $115: \mathrm{e} 233-8$.

15. Swarnalatha G. Comparison of nutritive value of seaweed with other terrestrial foods a review. Int J Food Nutr Sci 2018;7:61-70.

16. Mahan LK, Escott-Stump S. Krause's Food, Nutrition and Diet Therapy. $10^{\text {th }}$ ed. London: W.B.Saunders Company; 2000.

17. Ravishankar GA, Sarada R, Kamath BS, Namitha KK. Food applications of algae. In: Pometto A, Shetty K, Paliyath G, Levin RE, editors. Food Biotechnology. $2^{\text {nd }}$ ed. Boca Raton, FL: CRC Press; 2005. p. 493-6.

18. Gajalakshmi D, Shettu N, Murugesan S. Vitamin content of marine red alga Botryocladia leptopoda (J. Agardh) kylin potential use as a source of vitamins in nutrition. J Life Sci 2018;6:263-8.

19. Kumar BS, Murugesan S. Evaluation of fatty acid, mineral and vitamin compositions of Laurencia papillosa from the south east coast of India. Indo Am J Pharm Sci 2018;5:2681-7.

20. Sethi P. Biochemical composition of marine brown algae, Padina tetrastromatica Hauck. Int J Curr Pharm Res 2012;4:117-8.

21. Kumar RV, Murugesan S, Bhuvaneswari S. Phytochemical analysis of red alga Champia parvula (C. Agardh) collected from mandapam coast of Tamil Nadu, India. Int J Adv Pharm 2015;4:16-20.

22. National Academy of Sciences. Institute of medicine. Food and nutrition board. In: Dietary Reference Intakes for Thiamine, Riboflavin, Niacin, Vitamin B6, Folate, Vitamin B12, Pantothenic Acid, Biotin and Choline. Ch. 8. Washington, DC: National Academy Press; 1998.

23. Dietary reference values for food energy and nutrients for the United Kingdom. Report of the panel on dietary reference values of the committee on medical aspects of food policy. Rep Health Soc Subj (Lond) 1991;41:1-210.

24. Institut de Phytonutrition. Functional, Health and Therapeutic Effects of Algae and Seaweed. Institut de Phytonutrition Electronic Database. Version 1.5. Beausoleil, France: Institut de Phytonutrition; 2004.

25. Croft MT, Lawrence AD, Raux-Deery E, Warren MJ, Smith AG. Algae acquire Vitamin B12 through a symbiotic relationship with bacteria. Nature 2005;438:90-3

26. Takenaka S, Sugiyama S, Ebara S, Miyamoto E, Abe K, Tamura Y, et al. Feeding dried purple laver (nori) to Vitamin B12-deficient rats significantly improves Vitamin B12 status. Br J Nutr 2001;85:699-703.

27. Rebouche CJ. Ascorbic acid and carnitine biosynthesis. Am J Clin Nutr 1991;54:1147S-1152S

28. Qasim R, Barakati S. Ascorbic acid and dehydroascorbic acid contents of marine algal species from Karachi. Pak J Sci Ind Res 1985;28:129-33.

29. Zarogoulidis P, Kioumis I, Ritzoulis C, Petridis D, Darwiche K, Porpodis $\mathrm{K}$, et al. New insights in the production of aerosol antibiotics. Evaluation of the optimal aerosol production system for ampicillinsulbactam, meropenem, ceftazidime, cefepime and piperacillintazobactam. Int J Pharm 2013;455:182-8.

30. Durmaz Y, Duyar H, Gokpinar S, Taskaya L, Ogretmen Y, Bandarra N, et al. Fatty acids, $\alpha$-tocopherol and total pigment contents of Cystoseira spp., Ulva spp. and Zostera spp. from Sinop Bay (Turkey). Int J Nat Eng Sci 2008;2:111-4

31. Panayotova V, Stancheva M. Mineral composition of marine macroalgae from the Bulgarian black sea coast. Scr Sci Med 2013;45:42-5. 